\title{
Apparent response of small cell lung cancer to an extract of mistletoe and homoeopathic treatment
}

\author{
G W BRADLEY, A CLOVER
}

From William Harvey Hospital, Ashford, Kent

\begin{abstract}
A patient with small cell lung carcinoma was treated initially with extracts of mistletoe and homoeopathic treatment and appeared to respond. Subsequently radiotheraphy was given and the patient lived for five years seven months, which is much longer than is usual with this type of tumour.
\end{abstract}

Small cell lung cancer is a particularly aggressive tumour with a median survival in the absence of treatment of six to 17 weeks from the time of diagnosis. ${ }^{2}$ It usually responds to chemotherapy, but survival beyond three years is uncommon. ${ }^{23}$ We report a case of a patient who opted to have homoeopathic medicine and Iscador (extract of mistletoe) rather than chemotherapy and who lived five years seven months from the time of diagnosis.

\section{Case report}

A 59 year old man presented to hospital with a three day history of right sided chest pain, dyspnoea, and haemoptysis in February 1983. A chest radiograph showed a prominent right hilum with some shadowing in the right mid zone (fig 1); a bronchial neoplasm was diagnosed at bronchoscopy. Histological examination of bronchial tissue showed small cell anaplastic carcinoma.

Chemotherapy was offered but the patient refused it. He elected instead to have homoeopathic medicines and Iscador, which were started in April 1983. Brain metastases were suspected clinically, and because of this dexamethasone $4 \mathrm{mg}$ six hourly was started. This was given for four days, then gradually withdrawn over the next five days because he developed hypomania. He was given subcutaneous Iscador once daily for five days, followed by oral Iscador $0.05-0.1 \mathrm{mg}$ three times a day. The dose was progressively increased over a few weeks to achieve a maintenance dose that varied from 5 to $10 \mathrm{mg}$ three times a day. Various homoeopathic medicines were given, selected in accordance with the histological type of the lung tumour and the overall reaction of the patient. These were taken until April 1986, when he lapsed from homoeopathic follow up. They were resumed in January 1988 after the patient had requested a further homoeopathic consultation and continued until shortly before his death.

Address for reprint requests: Dr G W Bradley, William Harvey Hospital, Ashford, Kent TN24 0LZ.

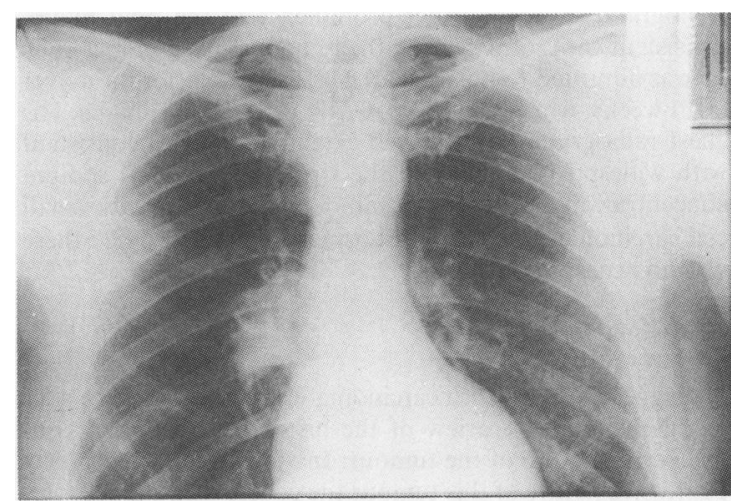

Fig 1 Chest radiograph taken at the time of admission showing a right hilar shadow.

A chest radiograph in August 1983 showed extensive changes, consistent with advance of the tumour since the initial diagnosis. By June 1984 the chest radiograph was near normal (fig 2) and he was well.

In October 1984 he developed pain down the left arm in the region of distribution of $\mathrm{C} 7-\mathrm{T} 1$, with some impairment of sensation. At that time his chest radiograph was normal but he had a group of hard lymph nodes in the right supraclavicular fossa. Neurological investigations showed normal cerebrospinal fluid and brain scanning showed minor cerebral atrophy. Biopsy of the lymph nodes confirmed small

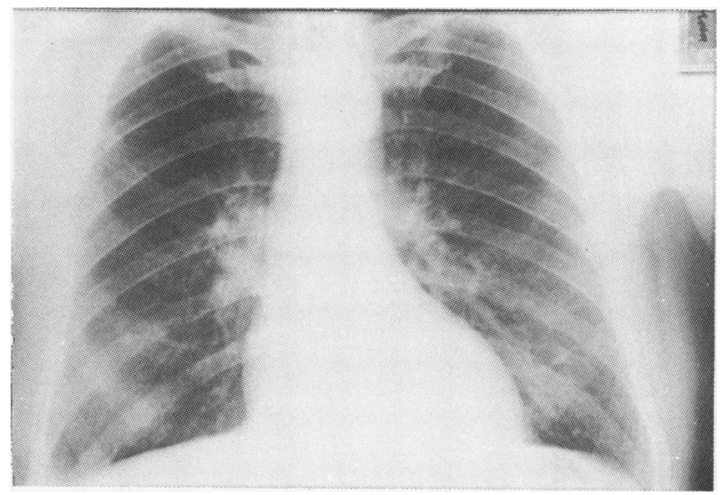

Fig 2 Chest radiograph 16 months after initial diagnosis; during this interval the only medication taken had been extract of mistletoe and homoeopathic medication. 
cell carcinoma consistent with the bronchial primary tumour. There were no neurosecretory cells present to suggest carcinoid tumour. Infiltration of his left brachial plexus with tumour was suspected and he was offered radiotherapy, which was given to both supraclavicular fossae and to the mediastinum (May 1985). The pain did not improve and continued to trouble him until his death; otherwise the quality of his life was good.

Regular follow up proved difficult because of his hypomanic personality. A chest radiograph in February 1987 was virtually normal. When he was reviewed in February 1988 his overall clinical condition had not changed but a chest radiograph showed further prominence of the right hilum, consistent with recurrence of the tumour. In September 1988 he was admitted to hospital after gradual deterioration over eight weeks, with weight loss, weakness, and dysphagia. His chest radiograph now showed extensive changes consistent with widespread tumour in the right lung and his sodium concentration was low $(122 \mathrm{mmol} / \mathrm{l})$, consistent with small cell carcinoma. He died in a hospice in October 1988; there was no necropsy.

\section{Discussion}

A diagnosis of small cell carcinoma was made from two sites at different times; review of the histological material confirmed the nature of the tumour. In view of the particularly aggressive nature of this tumour the course of the illness was remarkable. The initial radiological shadowing (fig l) after getting worse initially had resolved almost completely (fig 2) before radiotherapy was given. The progress of the disease from May 1985 would have been influenced by the radiotherapy, but prolonged survival is not expected to result from radiotherapy alone.

Extracts of mistletoe have been used for medicinal purposes for several centuries and are known to contain alkaloids with cytotoxic effects in vitro and in vivo. ${ }^{4}$ Extracts of mistletoe induce splenomegaly and thymic hyperplasia in tumour bearing mice ${ }^{5}$ and have also been shown to have adjuvant properties for the cellular immune response to sheep red blood cells when given intracutaneously in mice. ${ }^{6} \mathrm{It}$ is difficult to relate these findings in experimental animals to the use of Iscador in man, and the potential pharmacological effects made it impossible to discover whether the homoeopathic medication had any additional influence. Nevertheless, this case emphasises the potential importance of naturally occurring bioactive chemicals.

\section{References}

1 Geddes DM. The natural history of lung cancer; a review based on rates of tumour growth. Br J Dis Chest 1979;73:1-17.

2 Hande KR, Des Prez RM. Current perspectives in small cell lung cancer. Chest 1984;85:669-77.

3 Hansen HH. Chemotherapy of small cell carcinoma: a review. $Q J$ Med 1987;240:275-82.

4 Anderson LA, Phillipson JD. Mistletoe-the magic herb. Pharmaceut J 1982;229:437-9.

5 Nienhans J, Stoll M, Vester F. Thymus stimulation and cancer prophylaxis by viscum proteins. Experientia 1970;26:523-5.

6 Bloksma N, Van Diik H, Korst P, Willers JM. Cellular and humoral adjuvant activity of mistletoe extract. Immunobiolog 8 1979;156:309-19. 